\title{
Exploring New Boundaries to Mitigate Structural Vibrations of Bridges in Seismic Regions: A Smart Passive Strategy
}

\author{
Giuseppe Maddaloni, ${ }^{1,2}$ Nicola Caterino, ${ }^{2,3}$ Gianluca Nestovito, ${ }^{4}$ and Antonio Occhiuzzi ${ }^{2,3}$ \\ ${ }^{1}$ Department of Engineering, University of Benevento "Sannio," 82100 Benevento, Italy \\ ${ }^{2}$ Construction Technologies Institute, National Research Council (CNR), San Giuliano Milanese, 20098 Milan, Italy \\ ${ }^{3}$ Department of Engineering, University of Napoli "Parthenope," 80143 Naples, Italy \\ ${ }^{4}$ Rete Ferroviaria Italiana S.p.A., Regional Direction of Bologna, 40129 Bologna, Italy
}

Correspondence should be addressed to Nicola Caterino; nicola.caterino@uniparthenope.it

Received 2 January 2016; Revised 7 April 2016; Accepted 20 April 2016

Academic Editor: Athanasios Chasalevris

Copyright (C) 2016 Giuseppe Maddaloni et al. This is an open access article distributed under the Creative Commons Attribution License, which permits unrestricted use, distribution, and reproduction in any medium, provided the original work is properly cited.

\begin{abstract}
The combined use of two emerging technologies in the field of seismic engineering is investigated. The first is a semiactive control, to reduce smartly the effects induced by earthquakes on structures. The second is the Seismic Early Warning System which allows an estimate of the Peak Ground Accelerations of an incoming earthquake. This paper proposes the exploitation of this information in the framework of a semiactive control strategy based on the use of magnetorheological (MR) dampers. The main idea consists of changing the MR dampers' behaviour by the PGA estimated by the SEWS, to obtain the optimal seismic response of the structure. The control algorithm needed to drive the variable devices, according to the PGA estimate, is the core issue of the proposed strategy. It has been found that different characteristics of earthquakes that occur at different sites play a significant role in the definition of a control algorithm. Therefore, a design procedure for "regional" control algorithms has been performed. It is based on the results of several nonlinear dynamic simulations performed using natural earthquakes and on the use of a multicriteria decision-making procedure. The effectiveness of the proposed control strategy has been verified with reference to a highway bridge and to two specific worldwide seismic regions.
\end{abstract}

\section{Introduction}

Earthquakes represent one of the most destructive natural hazards. Among the possible serious consequences of a largemagnitude earthquake is the disruption of transportation systems, which limits postdisaster emergency response. The movement of emergency vehicles, such as police cars, fire trucks, and ambulances, can be severely restricted. Bridges have suffered various types of damage in past earthquakes, such as during the San Fernando (1971), Loma Prieta (1989), and Northridge (1994) earthquakes in California, the Kobe Earthquake (1995) in Japan, the Chi Earthquake (1999) in Taiwan, the Darfield (2010) and Christchurch (2011) Earthquakes in New Zealand, the Maule (2010) Earthquake in Chile, and the Tohoku (2011) Earthquake in Japan. Several types of damage have been recorded, sometimes affecting a few components, and in some cases leading to the overall structural collapse. A virtually complete collection of information related to the structural, social, and economic consequences on bridges (and other structures) due to earthquakes worldwide over the past 40 years can be found in the EERI archive that is part of the Learning from Earthquake Program [1].

Much research over the last few decades has been devoted to the definition of innovative techniques to address the seismic design and retrofit of bridges. In particular when dealing with the structural improvement of existing bridges in densely built earthquake-prone regions, the decision strategy for selecting the optimal intervention should not be based on the concept of seismic vulnerability alone and rather should take into account the cost-benefit balance of upgrade measures.

Most of the recent research contributions regarding the seismic upgrade of bridges have been stimulated by 
the international challenge launched in [2-4]. From 2009 to the present, several options of intervention have been proposed by the researchers in the field with reference to the benchmark structure defined in those articles. The final outcome is a wide range of alternative approaches, all appreciably innovative and effective in reducing the structural response of that highway bridge. They belong to all the three families of passive, semiactive, and active control techniques. Jung et al. [5] investigated the effectiveness of an adaptive passive control system based on magnetorheological (MR) dampers and on the concept of Electromagnetic Induction (EMI) proposed by Cho et al. [6]. Pradono et al. [7] proposed a simple control approach to produce negative stiffness hysteretic loops to reduce the vibration of base isolated bridges with MR dampers. A new control design approach to monitor the voltage supplied to MR dampers was developed by Ali and Ramaswamy [8]. Casciati et al. [9] applied a Passive Shape Memory Alloy Device (PSMAD), incorporating the analytical model of the structure in the control force equation of sample passive devices. An upgraded version of the PSMAD was subsequently elaborated by Zhang et al. [10], employing superelastic alloy wires with self-centring capabilities to use these damping devices in outdoor environments, especially in cold regions. Pujol et al. [11] used a passive static hyperbolic function depending only on velocity to ensure energy dissipation capabilities with a bounded control force. Ning et al. [12] developed an adaptive fuzzy sliding mode control algorithm for active actuators and then adapted the concept for use in combination with semiactive MR dampers. The dynamic behaviour of the benchmark bridge using three additional control strategies based on linear viscous dampers, friction-type devices, and 2-step SA viscous dampers was proposed by Madhekar and Jangid [13]. The same authors [14] also proposed a pseudonegative stiffness control algorithm with SA dampers and the adoption of variable frequency pendulum isolators (VFPI), installed between deck-end and abutments [15]. Narasimhan [16] presented a direct adaptive control scheme for active control using the combination of a proportional-derivative controller with a neural network, which does not need a priori knowledge of the nonlinear dynamics of the bridge and of its parameters, according to direct Lyapunov approach. In contrast, a so-called turboLyapunov approach control algorithm that utilizes the relationship between the absolute velocity of the MR dampers and control signal was developed by Cha and Agrawal [17].

The effectiveness of passive techniques for vibration control generally depends on how similar the characteristics of the actual seismic load are with respect to the design earthquake. The semiactive (SA) strategies are instead based on the use of variable stiffness and/or damping devices, able to adapt and optimize their mechanical response in realtime during the dynamic excitation. For such reasons, they are typically more effective than the passive ones, even if they are more difficult to implement and manage. Indeed, SA control techniques usually rely on the use of feedback control algorithms that require a real-time measurement of the structural response to instantaneously calibrate variable devices and, in turn, a complex framework of sensors and processing hardware to provide that. Despite many experimental investigations [18-22] and some real applications [23] having shown the high effectiveness of the SA control strategy to mitigate structural vibrations, it is yet to be proven that the reliability of the SA system is so much higher than that of alternative control techniques so as to justify its complexity. Conversely, doubts about the durability and reliability of these devices over time have recently been downsized [24].

In the last few years, the authors of this paper made efforts to define a "smart passive" control technique for the protection of structures. They aimed to find a trade-off between the ease of use of passive devices and the effectiveness of more complex (semiactive) approaches to reduce earthquake-induced structural vibrations [25-28]. The idea is based on the passive use of time-varying property devices $[29,30]$. Their calibration is commanded some seconds before an earthquake hits the structure, exploiting predictive information about the magnitude of the event provided by a Seismic Early Warning System (SEWS). The characteristics of earthquakes that really strike a given site can be, as known, even far from those expected on a probabilistic basis. In such cases, the performance of a "pure" passive control strategy can be worse than the design expectations, even leading to undesired effects. The proposed smart approach for giving supplemental damping allows avoiding this kind of problem. Furthermore, recent research [28] demonstrates the robustness and the fail-safety of such technique.

SEW systems experienced drastic improvement and wide diffusion in many active seismic regions of the world in the last few decades [31]. They are currently operating in Japan [32-35], Taiwan [36, 37], and Mexico [38]. Many other systems are under testing in other regions of the world, such as California [39-42], Turkey [43], Romania [44], and China [45]. In southern Italy, the early warning system PRESTo [46] (Probabilistic and Evolutionary Early Warning SysTem) has been under testing since December 2009. It is currently used to monitor the Apenninic fault system and to detect smallto-moderate-size events in the area where the MW 6.91980 Irpinia earthquake occurred.

Among other functions, a SEWS is able to provide an estimate of the peak ground accelerations (PGA) of an earthquake in a given site based on the frequency content of the P-waves and the use of attenuation laws. In this manner, the magnitude prediction is made available from the SEWS at the site some seconds before the destructive S-waves reach that location [47-52].

Herein, the use of MR dampers as passive devices, calibrated once according to the probable PGA of the incoming earthquake as provided by a SEWS installed at the site and remaining unchanged for the overall duration of the seismic excitation, is investigated. Concerning the response time of the system, in [47] it is showed that a seismic network for early warning can detect accelerations in the fault area and estimate the PGA at the structure's site in 10-13 s with a relatively high reliability. Therefore, the proposed system can be considered effective in all cases where the sensor network of the SEWS is closer to the epicenter than the infrastructure to protect by roughly $10 \mathrm{~km}$ or more. Then, the time needed for the calculation of the optimal voltage, once known as the PGA, is almost null. Finally, a recent experimental study [53], 
with reference to real MR devices, manufactured in Germany, demonstrated, via tests of promptness, that, using and properly tuning adequate electric hardware, the response time of such type of smart devices can be comfortably bounded to only $8-10 \mathrm{~ms}$.

The proposed approach, preliminarily explored in [27, 28 ], is herein fully formalized and designed for potential use in real applications.

The core issue of the proposed strategy is the design of the control logic that has to drive the MR dampers via the SEWS information. A specific design procedure has been herein addressed for the first time. The idea of realizing a design procedure for "regional" control algorithms, that is, control logic optimized to be used in specific areas characterized by homogeneous seismicity, is proposed. The latter is based on the results of several nonlinear dynamic simulations under natural earthquakes recorded in the considered area and on the use of optimization procedures.

The benchmark highway bridge, cited above, has been herein referred to as a case study to show the practical application and the effectiveness of said design procedure. Two different regional controllers have been specifically designed for Italy and California.

\section{The Proposed Approach}

The smart passive control strategy herein proposed to mitigate the seismic risk of bridges is based on the use of the following main components:

(1) Variable dissipative devices.

(2) A seismic early warning network working in the area where the structure is located.

(3) A control algorithm able to drive the variable dampers according to the preliminary information about an incoming earthquake provided by the early warning system.

Assuming that the dissipative devices have been proportioned (in terms of maximum reacting force) and positioned in the structure according to the criteria usually adopted for passive dampers and that a SEWS actually serves the region of interest, element number 3 definitely emerges as the core of the procedure and, thus, of the present research. It requires the implementation of a specific, unedited design procedure addressed to maximize the effectiveness of the entire control system in terms of structural response reduction. The ambitious goal is to calibrate such a design procedure to generate "regional" controllers, that is, control logic that can effectively drive the smart control devices regardless of where the structure is actually positioned inside the given region.

2.1. A Design Procedure for Smart Passive Regional Control Algorithms. The design procedure herein proposed can be summarized with the following step-by-step scheme:

(1) Definition of a set of natural regional accelerograms.

(2) Design of an optimal (pure) passive control strategy to be assumed as the benchmark case.
(3) Definition of a parametric control law for the smart passive control strategy.

(4) Definition of the final algorithm by selecting optimal values for the involved parameters.

Details about the goal of each step and possible ways to manage specific issues to push forward with the procedure are discussed in the following sections.

2.1.1. Definition of a Set of Natural Regional Seismic Accelerograms. It should be a set corresponding to natural seismic events registered in the region of interest. The set has to be large enough to include earthquakes very different from each other with regard to the distance to the fault, magnitude, and peak values of accelerations, velocity, and displacement and to well cover the range of typical values for such parameters in that region. To give an idea, when the specific location of a given structure is considered (rather than an entire region), many technical codes (e.g., Eurocode 8 [56]) require a minimum of 3 earthquakes to be considered for timehistory structural analyses. Actually, these codes strongly drive the designer to include in the set at least 7 seismic inputs. When an entire seismic region is considered, the authors consider that the set should be at least three times larger, depending on the extension of the area and on how varied the characteristics are (magnitude, distance to the fault, frequency content, etc.) of the seismic events expected.

2.1.2. Design of an Optimal (Pure) Passive Control Strategy. An optimal (pure) passive control strategy for the structure, to benchmark the smart passive strategy, has to be designed. This is recommended to correspond to a specific calibration, defined once and for all, of the variable dampers the user intends to use for smart control. The selection should preferably be performed with the support of an automatic decision-making tool to make the final choice as objective as possible. The TOPSIS method (Technique for Order Preference by Similarity to Ideal Solution) [5759] is herein suggested for that purpose. Actually, a wide comparative analysis performed among several multicriteria decision-making procedures from the literature established that TOPSIS is one of the most suitable procedures to solve civil engineering decision problems [60]. Moreover, it has been applied in the past with success to analogous problems relative to the seismic upgrading of structures [61].

The set of criteria to be used to compare the alternative passive strategies has to correspond to the main performance indices for the case under examination and should involve at least one pair of conflicting criteria (i.e., criteria that, considered separately from the others, lead to diametrically opposed decisions).

\subsubsection{Definition of a Parametric Smart Passive Control Law.} The control algorithm must establish what the optimal calibration of the installed variable dampers is according to an intensity measure of the incoming earthquake, the latter being forecasted by the Seismic Early Warning System. Preliminary studies performed by the authors $[27,28]$ led to 


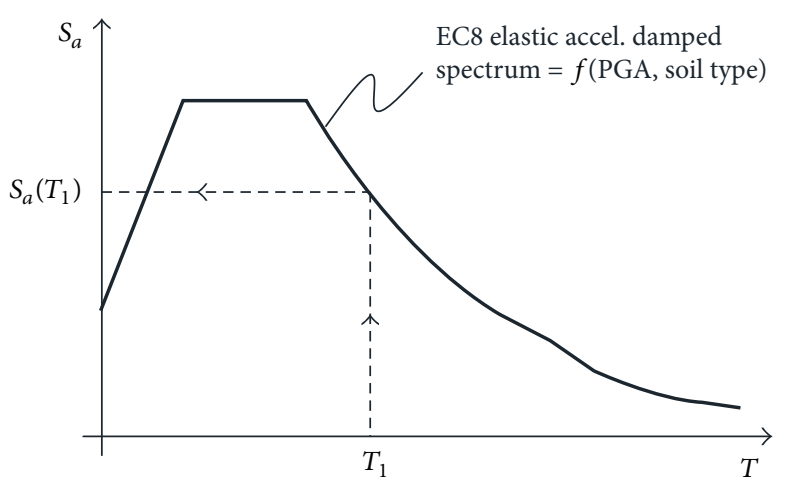

(a)

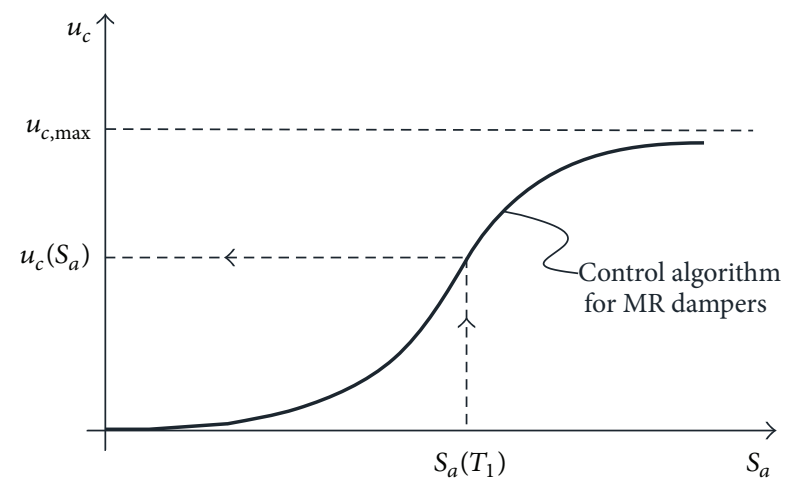

(b)

FIGURE 1: Code-based spectral accelerations derived by the forecasted PGA (a). Schematic shape of the smart passive control algorithm (b).

the definition of an effective control law suitable when variable dampers based on magnetorheological fluids are used and when the spectral accelerations $S_{a}$ at the fundamental period $T_{1}$ of the structure is used as a measure of the magnitude of the earthquake. The latter accelerations is suggested to be derived, once the SEWS provides the expected PGA of the incoming earthquake, from the elastic damped response spectrum defined according to Eurocode 8 [56] rules and, therefore, to the above PGA value, the soil type, and the structural damping (Figure 1(a)). The above cited control law is that in (1), where $u_{c}$ is the voltage to be supplied to the MR dampers, as established by the algorithm according to $S_{a}\left(T_{1}\right)$, whereas the three parameters of the configuration involved are as follows:

(i) $\alpha$ is expressed in $g$ (gravitational accelerations, as $S_{a}$ ) and determines the abscissa of the point of the maximum slope of the curve in Figure 1(b).

(ii) $\beta$, also expressed in $g$, determines the magnitude of the above slope.

(iii) $u_{c, \max }$ is the maximum voltage set to be given to the MR devices.

This formulation has been assumed because it corresponds to a smooth curve, giving values of $u_{c}$ from 0 to $u_{c, \max }$ (Figure 1(b)):

$$
u_{c}\left[S_{a}\left(T_{1}\right)\right]=\left[1+\tanh \left(\frac{S_{a}\left(T_{1}\right)-\alpha}{\beta}\right)\right] \cdot \frac{u_{c, \max }}{2} .
$$

2.1.4. Selection of Optimal Values of the Involved Parameters: Final Algorithm. An optimization procedure is recommended to calibrate all of the parameters involved in the control law. For instance, when MR dampers are adopted for control and (1) is assumed as the control law, the three parameters $\alpha, \beta$, and $u_{c \text {, max }}$ have to be defined. These depend on the seismic region.

Herein, the TOPSIS procedure is again suggested to achieve the above goal, that is, to compare the amount of structural response reduction of several combinations of values for $\alpha, \beta$, and $u_{c, \max }$ to find the "best" among them. To do that, first the range of values for each of the parameters and the criteria to be used for judgment must be defined. More details about such aspects will be given in the following sections in which a practical application of the method to a case study structure will be shown. Here, it is worth underlining the need for involving criteria that reflect the peculiar features of a semiactive control system. For instance, not only the mean value of each performance index evaluated for all of the earthquakes of the set but also the standard deviation of those values with respect to the mean should be considered. Actually, a semiactive strategy, adaptive by definition, should always ensure less variability of the structural response against even very different seismic inputs.

2.1.5. The TOPSIS Decision-Making Tool: Summary of the Procedure. Herein, a brief summary of the TOPSIS procedure [57-59], suggested in Sections 2.1.2 and 2.1.4, is presented for the convenience of the reader.

Let $A_{1}, A_{2}, \ldots, A_{n}$ be a finite group of $n$ alternative solutions for a decision-making problem and $C_{1}, C_{2}, \ldots, C_{m}$ a finite set of $m$ criteria according to which performance of each feasible action must be assessed. Solving the multicriteria decision problem consists of determining the optimal solution among alternatives, that is, the one with the highest degree of desirability with respect to all of the criteria. The first step consists in the evaluation of all the alternatives according to each criterion. Generally speaking, qualitative criteria can be involved in the decision process. This kind of criteria, by definition, requires evaluation through linguistic judgments. As a consequence, in these cases, a further step, consisting in the conversion of these qualitative evaluations in equivalent crisp numbers, is needed, with procedures available in literature. At the end, the so-called decision matrix (having $n$ by $m$ dimensions) may be composed, where the generic element $x_{i j}$ (ith row, $j$ th column) is the performance of the alternative $A_{i}$ in respect of criterion $C_{j}$ (Table 1). Then the method needs the definition of a weight for each criterion expressing the relative importance of it in respect of the others. This is one of the most critical phases of the decision procedure requiring a synthetic and quantitative measure of the decision maker's preference about each performance target. However, weighting of criteria is 
TABLE 1: Decision matrix.

\begin{tabular}{cccccc}
\hline & & \multicolumn{5}{c}{ Criteria (weights) } \\
& & $C_{1}\left(w_{1}\right)$ & $C_{2}\left(w_{2}\right)$ & $\cdots$ & $C_{m}\left(w_{m}\right)$ \\
\hline \multirow{4}{*}{ Alternatives } & $A_{1}$ & $x_{11}$ & $x_{12}$ & $\cdots$ & $x_{1 m}$ \\
& $A_{2}$ & $x_{21}$ & $x_{22}$ & $\cdots$ & $x_{2 m}$ \\
& $\vdots$ & $\vdots$ & $\vdots$ & $\vdots$ & $\vdots$ \\
& $A_{n}$ & $x_{n 1}$ & $x_{n 2}$ & $\cdots$ & $x_{n m}$ \\
\hline
\end{tabular}

unsuitable for decision problems where criteria implicitly have the same importance. This is the case of the application herein proposed that involves two criteria, both related to structural performance.

The TOPSIS method is based on the geometrical concept that the best alternative should have the shortest distance to an ideal solution $\left(A^{*}\right)$ and the farthest distance to negativeideal one $\left(A^{-}\right)$. Let $x_{i j}$ indicate the performance measure of the $i$ th alternative $(i=1,2, \ldots, n)$ according to the $j$ th criterion $(j=1,2, \ldots, m)$. The normalization of the $x_{i j}$ values must first be done according to (2). Let $r_{i j}$ indicate the normalized value of $x_{i j}$

$$
r_{i j}=\frac{x_{i j}}{\sqrt{\sum_{k=1}^{4} x_{k j}^{2}}} .
$$

The two opposite fictitious solutions $A^{*}$ and $A^{-}$, as for the real alternatives $A_{i}$, are defined by $m$ values representing the (normalized) performances according to the $m$ criteria. In particular, the ideal solution $A^{*}$ is obtained by taking for each criterion the "best" performance among the alternatives, whereas the negative-ideal solution $A^{-}$is obtained by taking the "worst" values. It is worth noting that the best value among the performances corresponds to the minimum or maximum value depending on what type the criterion is, that is, a "cost" or "benefit" criterion, respectively.

Each of the alternatives, real $\left(A_{1}, A_{2}, \ldots, A_{n}\right)$ and fictitious $\left(A^{*}\right.$ and $\left.A^{-}\right)$, can be represented by a point in the $m$-dimensional space defined by the axes along which the normalized performances are measured according to each of the $m$ criteria. Figure 2 reports, as an example of such a representation, a hypothetical decision problem involving 4 alternatives and 3 criteria. Indicating with $S_{i^{*}}$ and $S_{i^{-}}$ the distances of each option $A_{i}$ to $A^{*}$ and $A^{-}$, respectively (equation (3)), the ranking of alternative solutions is made according to their relative closeness $C_{i^{*}}$ to $A^{*}$, evaluated as in (4):

$$
\begin{aligned}
S_{i^{*}} & =\sqrt{\sum_{j=1}^{m}\left(r_{i j}-r_{j^{*}}\right)^{2}} ; \\
S_{i^{-}} & =\sqrt{\sum_{j=1}^{m}\left(r_{i j}-r_{j^{-}}\right)^{2}} ; \\
C_{i^{*}} & =\frac{S_{i^{-}}}{S_{i^{*}}+S_{i^{-}}} .
\end{aligned}
$$

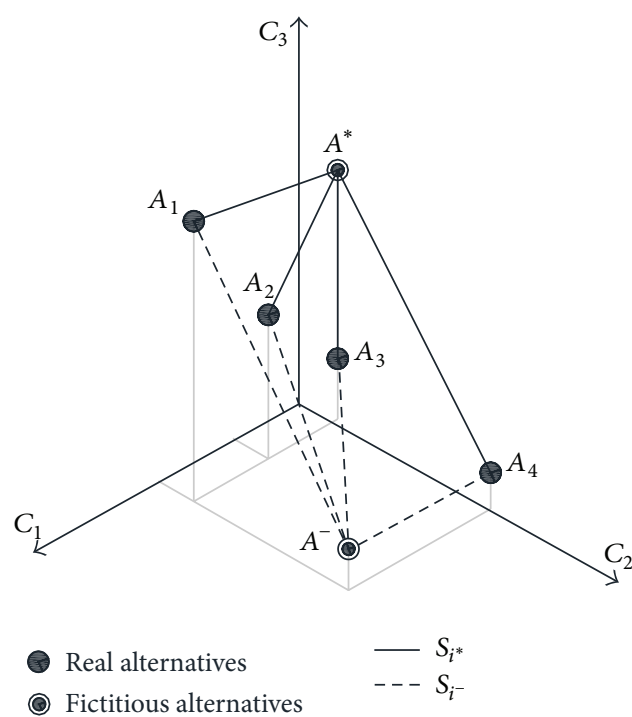

FIGURE 2: An example of the graphical representation of a decisionmaking problem according to TOPSIS.

It is worth noting that $C_{i^{*}}$ is equal to 1 if $A_{i}$ coincides with $A^{*}$, it is equal to 0 if $A_{i}$ coincides with $A^{-}$, and it is between 0 and 1 in the other cases. The best alternative is the one with the highest $C_{i^{*}}$ value.

\section{Application of the Proposed Approach to a Case Study}

The approach herein proposed to design the smart passive control for the seismic protection of structures has been tested through a practical application to a case study. The structure is a highway bridge proposed as a benchmark structural control problem in [2-4]. It is located in Orange County, southern California, and consists of a two-span continuous cast in situ prestressed concrete. The total length of each span is $58.5 \mathrm{~m}$, whereas the transversal prestressed support beam has a length of $31.4 \mathrm{~m}$. This central support is linked to two columns that are $6.9 \mathrm{~m}$ high. The mass of the deck is approximately 3200 tons, while the total mass of the bridge is 4200 tons (Figure 3). The bridge deck is seismically isolated by four nonseismic elastomeric pads at each abutment, whereas eight fluid dampers are installed between the end abutments and the deck to reduce seismic response. However, in the evaluation model, lead rubber bearings (LRB) are used to replace the eight traditional nonseismic elastomeric pads (Figure 4). The first mode of the structure is torsional with a natural period $T_{1}=0.813 \mathrm{~s}$. This configuration will be used for comparison to establish the effectiveness of the control system proposed. It will be referred to as the "uncontrolled" structure.

In the above papers introducing the benchmark bridge, the design of an SA control strategy is presented, considering a total of $20 \mathrm{MR}$ dampers installed between the deck and the abutments and at the top of the piers of the central support. The maximum voltage for the devices is $10 \mathrm{~V}$. The capacity in terms of reacting force is $1000 \mathrm{kN}$. Herein, the same devices 

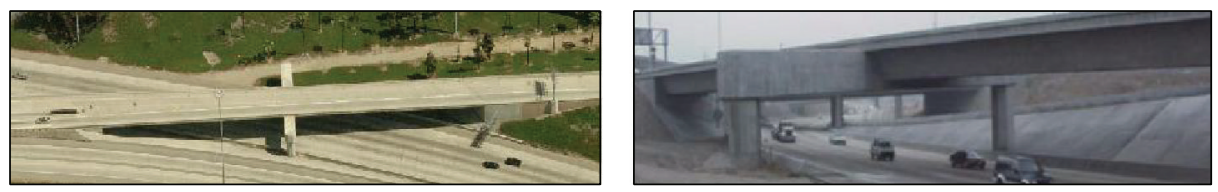

FIGURE 3: Two views of the benchmark highway bridge.

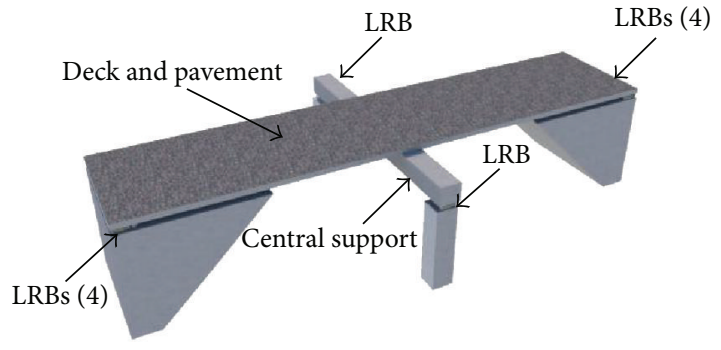

FIGURE 4: Uncontrolled configuration of the benchmark highway bridge.

(further details about them can be found in the cited articles) are used to realize the smart passive control as described in the previous section.

Such structure has been adopted as a reference case for the design of regional smart passive control algorithms. Two seismic regions have been considered: Italy and California. The two cases will be described in parallel in the following sections, according to the step-by-step procedure discussed in Section 2.1.

3.1. Definition of the Set of Natural Regional Accelerograms. According to the criteria discussed in Section 2.1.1, a set of 30 natural accelerograms has been selected for each of the 2 seismic regions. All are recorded on soil type B according to the Eurocode 8 [56] classification. They have been assumed as input for nonlinear time-history analyses of the bridge. The analyses have been performed using the MATLAB code made available by the above authors of the benchmark papers [2-4]. For the excitation of the longitudinal (EW) and transverse (NS) directions of the bridge, both components have been used simultaneously. The main characteristics of the earthquake ground motions are shown in Tables 2 and 3 for Italy and California, respectively. They cover a wide range of magnitudes and PGAs ( 0.06 to $0.66 \mathrm{~g}$ for Italy, 0.08 to $0.89 \mathrm{~g}$ for California), as recommended above. It is worth noting that the benchmark problem cannot consider vertical seismic accelerations. For this reason, vertical components of the selected earthquakes have not been mentioned in this paper. The Italian seismic inputs have been downloaded from the Italian accelerations Archive (ITACA [54]), whereas the Californian earthquakes are sourced from the Pacific Earthquake Engineering Research Center (PEER [55]).

3.2. Design of the Optimal (Pure) Passive Control Strategy. Several passive control strategies have been compared, separately, for each of the two regions. Each strategy corresponds to a different passive use of the MR dampers described above. Voltage values within the operation interval of the devices, $[0,10] \mathrm{V}$, with a step of $0.05 \mathrm{~V}$ have been considered, leading to a total of 201 different passive configurations. The number of response parameters herein assumed to explore the proposed strategy and the effective use of the optimization procedure it involves have been limited to two, each representative of the main groups of usual response indexes, that is, forces and displacements. Nevertheless, future developments of this work may take into consideration additional response parameters. Those assumed herein are

(i) $I_{1}$, the peak overturning moment at the base of the piers in the controlled structure normalized by the corresponding value obtained for the uncontrolled structure subjected to the same seismic input;

(ii) $I_{2}$, the peak displacement at the midspan of the controlled structure normalized by the corresponding value of the uncontrolled structure under the same earthquake.

The TOPSIS procedure is applied assuming two evaluation criteria, $C_{1}$ and $C_{2}$, based on the values of the two above indices, respectively. More in detail, the performance measure $x_{i j}$ of the $i$ th alternative $(i=1,2, \ldots, 201)$ according to the $j$ th criterion $(j=1,2)$ is calculated as follows:

$$
x_{i j}=\frac{1}{30} \sum_{k=1}^{30} I_{i j k}
$$

where $I_{i j k}$ is the $j$ th performance index evaluated for the $i$ th alternative in response to the $k$ th earthquake $(k=$ $1,2, \ldots, 30)$. Therefore, the $j$ th criterion takes into account the mean value of the $j$ th performance index for all of the earthquakes of the set.

The TOPSIS method is applied to both of the decision problems relative to the Italian and Californian regions, leading to the following outcomes:

(i) Italy. The voltage $3.75 \mathrm{~V}$ resulted in the highest relative closeness (0.94) to the ideal solution; therefore, it has been assumed to be representative of the optimal passive damper for the Italian earthquakes. The performance indices are, in order, 0.87 and 0.67 , and therefore the optimal passive control strategy leads, on average, to a $13 \%$ reduction (with respect to the uncontrolled case) of the overturning moment demanded of the piers and to a $33 \%$ reduction of midspan displacement.

(ii) California. The voltage $10.00 \mathrm{~V}$ (the highest allowable value) resulted in the highest relative closeness (0.98) 
TABLE 2: The Italian ground motions selected for the analyses (ITACA database [54]).

\begin{tabular}{|c|c|c|c|c|c|c|c|}
\hline$N$ & Earthquake name & Station name & $\begin{array}{c}\text { Date } \\
{[\mathrm{dd} / \mathrm{mm} / \text { yyyy }]} \\
\end{array}$ & $\mathrm{Mw}$ & $\begin{array}{c}\text { PGA NS } \\
{[\mathrm{g}]}\end{array}$ & $\begin{array}{l}\text { PGA EW } \\
{[\mathrm{g}]}\end{array}$ & $\begin{array}{c}\text { Epic. dist. } \\
{[\mathrm{km}]}\end{array}$ \\
\hline 1 & Ancona & Ancona-Rocca & $21 / 06 / 1972$ & - & 0.18 & 0.08 & 22.87 \\
\hline 2 & Ancona & Ancona-Rocca & $14 / 06 / 1972$ & 4.8 & 0.54 & 0.39 & 7.73 \\
\hline 3 & L'Aquila Earthquake & L'Aquila-V. Aterno-Centro Valle & 07/04/2009 & 5.0 & 0.10 & 0.19 & 3.94 \\
\hline 4 & L'Aquila Main Shock & Aquila Castello & 06/04/2009 & 6.3 & 0.31 & 0.26 & 6.02 \\
\hline 5 & L’Aquila Main Shock & $\begin{array}{l}\text { L'Aquila-V. Aterno-Aquil Park } \\
\text { Ing. }\end{array}$ & 06/04/2009 & 6.3 & 0.35 & 0.33 & 5.65 \\
\hline 6 & L'Aquila Main Shock & L'Aquila-V. Aterno-F. Aterno & 06/04/2009 & 6.3 & 0.44 & 0.40 & 4.63 \\
\hline 7 & L'Aquila Main Shock & L'Aquila-V. Aterno-Colle Grilli & $06 / 04 / 2009$ & 6.3 & 0.49 & 0.45 & 4.39 \\
\hline 8 & L’Aquila Main Shock & L’Aquila-V. Aterno-Centro Valle & $06 / 04 / 2009$ & 6.3 & 0.66 & 0.55 & 4.87 \\
\hline 9 & Irpinia Earthquake & Bagnoli Irpino & $23 / 11 / 1980$ & 6.9 & 0.13 & 0.19 & 21.80 \\
\hline 10 & Irpinia Earthquake & Brienza & 23/11/1980 & 6.9 & 0.22 & 0.18 & 42.21 \\
\hline 11 & Irpinia Earthquake & Calitri & $23 / 11 / 1980$ & 6.9 & 0.16 & 0.17 & 18.90 \\
\hline 12 & Irpinia Earthquake & Conza-Piana & 01/12/1980 & - & 0.17 & 0.20 & 1.54 \\
\hline 13 & Friuli Earthquake 4th Shock & Forgaria Cornino & $15 / 09 / 1976$ & 5.9 & 0.35 & 0.33 & 16.83 \\
\hline 14 & Friuli Earthquake 2nd Shock & Forgaria Cornino & $11 / 09 / 1976$ & 5.6 & 0.13 & 0.23 & 26.21 \\
\hline 15 & Friuli & Forgaria Cornino & $16 / 09 / 1976$ & 5.3 & 0.24 & 0.20 & 6.67 \\
\hline 16 & Friuli Earthquake 1st Shock & $\begin{array}{l}\text { Tolmezzo Centrale-Diga } \\
\text { Ambiesta } 1\end{array}$ & 06/05/1976 & 6.4 & 0.35 & 0.31 & 21.72 \\
\hline 17 & Friuli & Gemona & $11 / 09 / 1976$ & 5.1 & 0.19 & 0.16 & 4.39 \\
\hline 18 & Friuli & Gemona & $13 / 09 / 1976$ & 4.6 & 0.13 & 0.19 & 6.01 \\
\hline 19 & Friuli Earthquake 4th Shock & Gemona & $15 / 09 / 1976$ & 5.9 & 0.25 & 0.26 & 4.67 \\
\hline 20 & Friuli Earthquake 2nd Shock & Gemona & $11 / 09 / 1976$ & 5.6 & 0.33 & 0.30 & 14.96 \\
\hline 21 & Friuli Earthquake 3rd Shock & Gemona & $15 / 09 / 1976$ & 5.9 & 0.32 & 0.65 & 5.23 \\
\hline 22 & Gran Sasso & Gran Sasso (Lab. INFN Assergi) & 09/04/2009 & 5.4 & 0.18 & 0.17 & 16.12 \\
\hline 23 & L'Aquila Earthquake & Gran Sasso (Lab. INFN Assergi) & 07/04/2009 & 5.6 & 0.25 & 0.28 & 16.81 \\
\hline 24 & Irpinia Earthquake & Mercato S. Severino & $23 / 11 / 1980$ & 6.9 & 0.11 & 0.14 & 46.30 \\
\hline 25 & App. Lucano & Lauria Galdo & 09/09/1998 & 5.6 & 0.23 & 0.24 & 6.63 \\
\hline 26 & Canale di Sicilia & Mazara del Vallo & $07 / 06 / 1981$ & 4.9 & 0.19 & 0.13 & 9.76 \\
\hline 27 & Val Nerina & Norcia & $28 / 02 / 1980$ & 5.0 & 0.19 & 0.19 & 10.63 \\
\hline 28 & Casentino & Pieve Santo Stefano & $26 / 11 / 2001$ & 4.7 & 0.18 & 0.19 & 9.27 \\
\hline 29 & Irpinia Earthquake & Sturno & 23/11/1980 & 6.9 & 0.23 & 0.31 & 33.26 \\
\hline 30 & Massiccio Ortles & S. Leonardo Valpassiria & $17 / 07 / 2001$ & 4.8 & 0.17 & 0.06 & 18.66 \\
\hline
\end{tabular}

to the ideal solution; therefore, it has been assumed to be representative of the optimal passive damper for the Californian earthquakes. The performance indices are 0.79 and 0.58 , and therefore the optimal passive control strategy leads, on average, to a $21 \%$ reduction of the overturning moment demanded of the piers and to a $42 \%$ reduction of midspan displacement.

Figures 5 and 6, for Italy and California, respectively, show the values of the indices $I_{1}$ and $I_{2}$ for each of the 30 earthquakes and each of the 201 passive dampers tested. The black dots highlight the performance of the optimal passive dampers.

3.3. Design of the Smart Passive Control Strategy. For both the Italian and Californian cases, several numerical analyses have been performed to calibrate the smart passive control strategy, that is, to find the optimal value for the parameters (namely, $u_{c \text {, max }}, \alpha$, and $\beta$ ) involved in the assumed analytical expression (equation (1)) for the control law. Actually, the value of $u_{c \text {, max }}$ has been established a priori, looking at the results of the previous step in which, to find the optimal passive configuration, the variability of the response according to the voltage given to the MR dampers has been investigated. More in detail, the value of $u_{c \text {, max }}$ should always be defined so as to make the range $\left[0, u_{c, \text { max }}\right]$ inclusive of the value found to be optimal for a pure passive control strategy, against the whole set of earthquake records (herein it is $3.75 \mathrm{~V}$ and $10.00 \mathrm{~V}$ for the two regions, Italy and California, resp.). Moreover the interval $\left[0, u_{c, \max }\right]$ should be large enough so as to strictly include all the values of voltage found to be ideal for each single record of the set, excluding the greater values, although included in the working range of the devices. 
TABLE 3: The Californian ground motions selected for the analyses (PEER database [55]).

\begin{tabular}{|c|c|c|c|c|c|c|c|}
\hline$N$ & Earthquake name & Station name & $\begin{array}{c}\text { Date } \\
{[\mathrm{dd} / \mathrm{mm} / \text { yyyy }]}\end{array}$ & $\mathrm{Mw}$ & $\begin{array}{c}\text { PGA NS } \\
{[\mathrm{g}]}\end{array}$ & $\begin{array}{c}\text { PGA EW } \\
{[\mathrm{g}]}\end{array}$ & $\begin{array}{c}\text { Epic. dist. } \\
{[\mathrm{km}]}\end{array}$ \\
\hline 1 & Cape Mendocino & Shelter Cove Airport & $25 / 04 / 1992$ & 7.0 & 0.23 & 0.18 & 36.28 \\
\hline 2 & Coalinga & Parkfield-Cholame & $02 / 05 / 1983$ & 6.4 & 0.14 & 0.14 & 57.31 \\
\hline 3 & Coalinga & Sulphur Baths & $25 / 07 / 1983$ & 5.2 & 0.23 & 0.15 & 12.02 \\
\hline 4 & Coyote Lake 108 & San Juan Bautista & 06/08/1979 & 5.7 & 0.11 & 0.11 & 23.24 \\
\hline 5 & Hector Mine 168 & Joshua Tree Fire Station & $16 / 10 / 1999$ & 7.1 & 0.17 & 0.15 & 52.29 \\
\hline 6 & Imperial Valley 195 & Superstition Mtn Camera & $15 / 10 / 1979$ & 6.5 & 0.20 & 0.11 & 59.54 \\
\hline 7 & Kern County 126 & Santa Barbara Courthouse & $21 / 07 / 1952$ & 7.4 & 0.13 & 0.09 & 88.39 \\
\hline 8 & Landers 789 & Lucerne & $28 / 06 / 1192$ & 7.3 & 0.79 & 0.73 & 44.02 \\
\hline 9 & Little Creek 200 & Wrightwood & $12 / 09 / 1970$ & 5.3 & 0.16 & 0.20 & 13.01 \\
\hline 10 & Livermore 251 & Livermore Morgan Terr Park & $27 / 01 / 1980$ & 5.4 & 0.25 & 0.20 & 10.33 \\
\hline 11 & Mammoth Lakes 211 & McGee Creek & $11 / 06 / 1980$ & 4.9 & 0.21 & 0.08 & 7.49 \\
\hline 12 & Morgan Hill 423 & Anderson Dam Downstream & $24 / 04 / 1984$ & 6.2 & 0.42 & 0.28 & 16.67 \\
\hline 13 & Northen Calif 179 & Cape Mendocino & 07/06/1975 & 5.2 & 0.18 & 0.12 & 30.54 \\
\hline 14 & Northridge 157 & Sylmar Converter Station East & $20 / 03 / 1994$ & 5.3 & 0.16 & 0.13 & 9.00 \\
\hline 15 & Northridge 178 & Malibu Canyon; Monte Nido Fs & $17 / 01 / 1994$ & 6.7 & 0.18 & 0.16 & 19.19 \\
\hline 16 & Northridge 843 & Sylmar Hospital & $17 / 01 / 1994$ & 6.6 & 0.84 & 0.60 & 16.77 \\
\hline 17 & Oroville 152 & Up \& Down Cafe & 08/08/1975 & 4.7 & 0.15 & 0.10 & 11.06 \\
\hline 18 & Oroville 189 & Johnson Ranch & 08/08/1975 & 4.7 & 0.19 & 0.10 & 1.07 \\
\hline 19 & San Fernando 151 & Santa Felicia Dam & $09 / 02 / 1971$ & 6.6 & 0.15 & 0.15 & 31.55 \\
\hline 20 & San Fernando 364 & Castaic Old Ridge Route & $09 / 02 / 1971$ & 6.6 & 0.27 & 0.36 & 25.36 \\
\hline 21 & Santa Barbara 203 & Santa Barbara Court & $13 / 08 / 1978$ & 5.9 & 0.20 & 0.10 & 3.20 \\
\hline 22 & Sierramadre 113 & San Marino Southwestern Academy & 28/06/1991 & 5.6 & 0.11 & 0.09 & 19.95 \\
\hline 23 & Sierramadre 169 & Pasadena & $28 / 06 / 1991$ & 5.6 & 0.17 & 0.14 & 27.77 \\
\hline 24 & Stone Canyon 212 & Stone Canton Geophysical Obs. & $04 / 09 / 1972$ & 4.8 & 0.21 & 0.16 & 9.56 \\
\hline 25 & Stone Canyon 515 & Melendy Ranch Station & 04/09/1972 & 4.8 & 0.52 & 0.48 & 10.19 \\
\hline 26 & Superstition Hills 893 & Ssm & $24 / 11 / 1987$ & 6.5 & 0.55 & 0.89 & 7.50 \\
\hline 27 & Upland 233 & Rancho Cucamonga & $28 / 02 / 1990$ & 5.6 & 0.23 & 0.22 & 12.19 \\
\hline 28 & Victoria 621 & Cerro Prieto & 09/06/1980 & 6.3 & 0.62 & 0.59 & 33.73 \\
\hline 29 & Whittier Narrows & Altadena Eaton & 04/10/1987 & 5.3 & 0.19 & 0.16 & 6.59 \\
\hline 30 & Whittier Narrows & Alhambra Fremont & 01/10/1987 & 5.9 & 0.33 & 0.41 & 6.77 \\
\hline
\end{tabular}

Actually, it has been proved that if the operating range for the algorithm $\left[0, u_{c, \max }\right]$ is oversized, the performance of the smart passive technique can worsen. Finally, with reference to the two regions herein examined, the following conclusions have been drawn:

(i) For the Italian case, given that the optimal passive voltage is equal to $3.75 \mathrm{~V}$ and because none of the records has called for the adoption of a voltage value higher than $4 \mathrm{~V}$, it has been assumed $u_{c, \max }$ equal to $4 \mathrm{~V}$.

(ii) For the Californian case, because the optimal passive voltage was found to be $10 \mathrm{~V}$, it has been assumed that $u_{c \text {, max }}$ is just equal to $10 \mathrm{~V}$ (i.e., the upper bound of the operating range of the MR devices).

A total of 961 combinations of values for $\alpha$ and $\beta$ have been tested, both assumed to be within the range $[0.10 ; 0.70] \mathrm{g}$ with a step of $0.02 \mathrm{~g}$. These intervals have been preliminarily individuated because they include values of $\alpha$ and $\beta$ that lead to an acceptable shape (see Figure 1(b)) of the control algorithm, such that the voltage $u_{c}$ actually varies from 0 to $u_{c \text {, max }}$ according to the values of the spectral accelerations demand expected at the region.

As highlighted in Section 2.1.4, to calibrate the control law, the evaluation criteria addressed to maximize the performance are peculiar for a semiactive control technique (e.g., a limited variability of the structural response against even very different seismic inputs) and are strongly recommended to effectively achieve the goals of the strategy herein proposed. For this reason, additional criteria with respect to those adopted to design the optimal passive strategy $\left(C_{1}, C_{2}\right)$ have been considered, for a total of six:

$C_{1}$ measures the mean value of the performance index $I_{1}$ (peak overturning moment at the base of the piers) for all of the earthquakes of the set. 

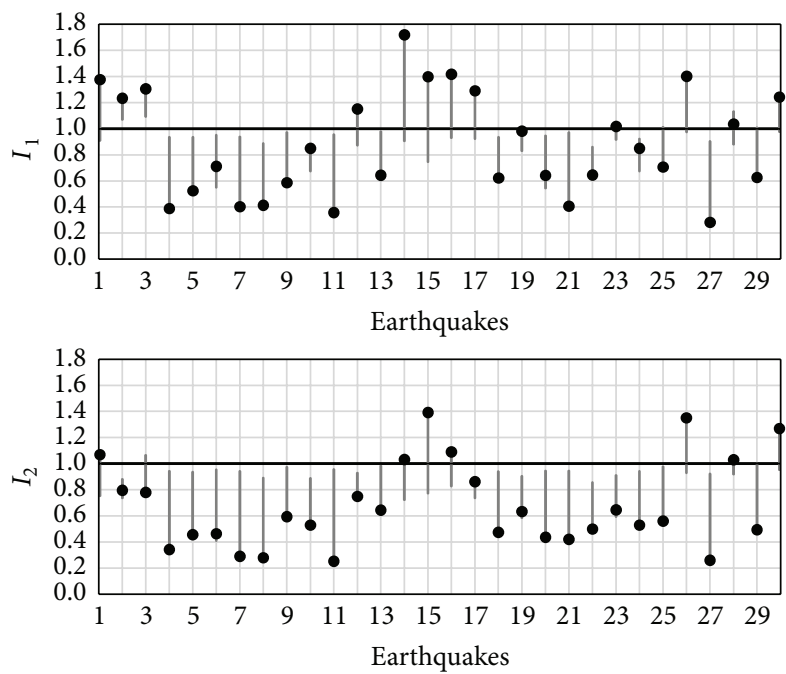

FIGURE 5: Italy: performance indices for the passive control strategies investigated.
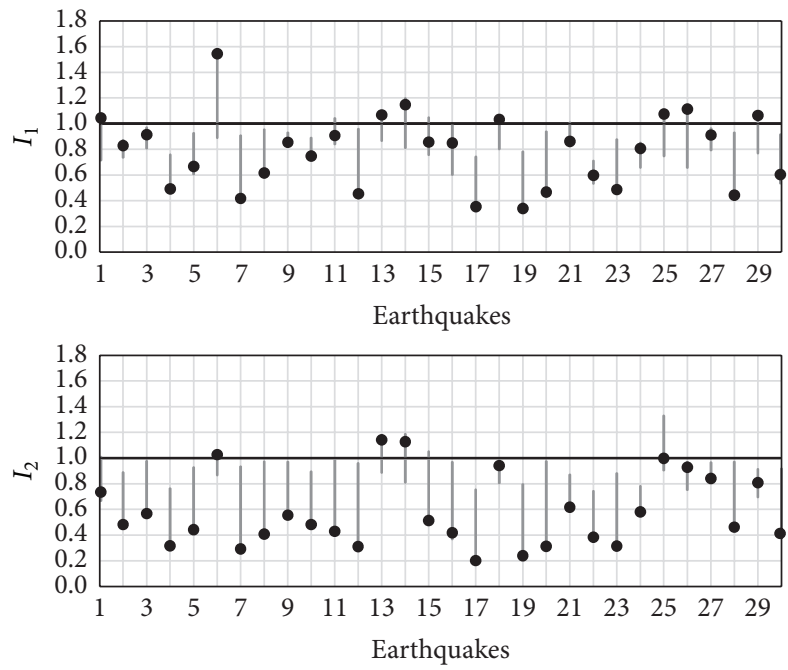

FIGURE 6: California: performance indices for the passive control strategies investigated.

$\mathrm{C}_{2}$ measures the mean value of the performance index $I_{2}$ (peak midspan displacement) for all of the earthquakes of the set.

$C_{3}$ measures the standard deviation of the performance index $I_{1}$ for all of the earthquakes of the set.

$\mathrm{C}_{4}$ measures the standard deviation of the performance index $I_{2}$ for all of the earthquakes of the set.

$C_{5}$ measures the number of earthquakes over the total (30) for which the smart passive strategy leads to a performance index $I_{1}$ greater than 1 (i.e., to a pier overturning moment greater than in the uncontrolled case).

$C_{6}$ measures the number of earthquakes over the total (30) for which the smart passive strategy leads to

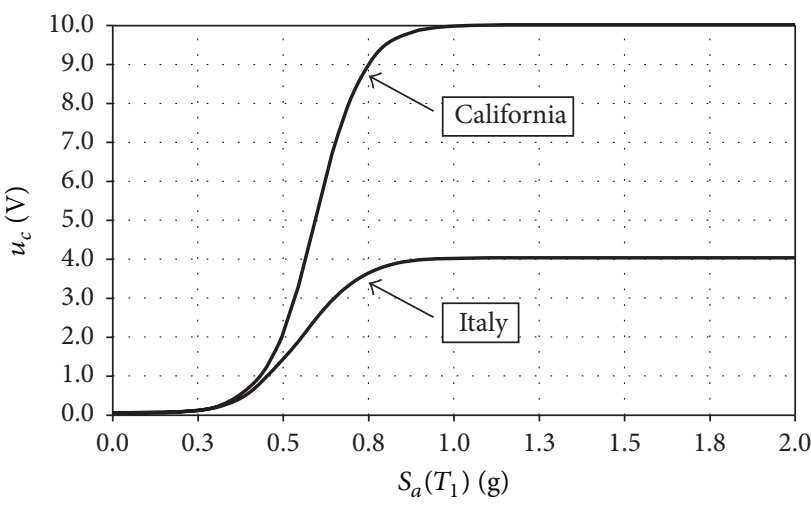

FIgURE 7: Regional control algorithms for Italy and California.
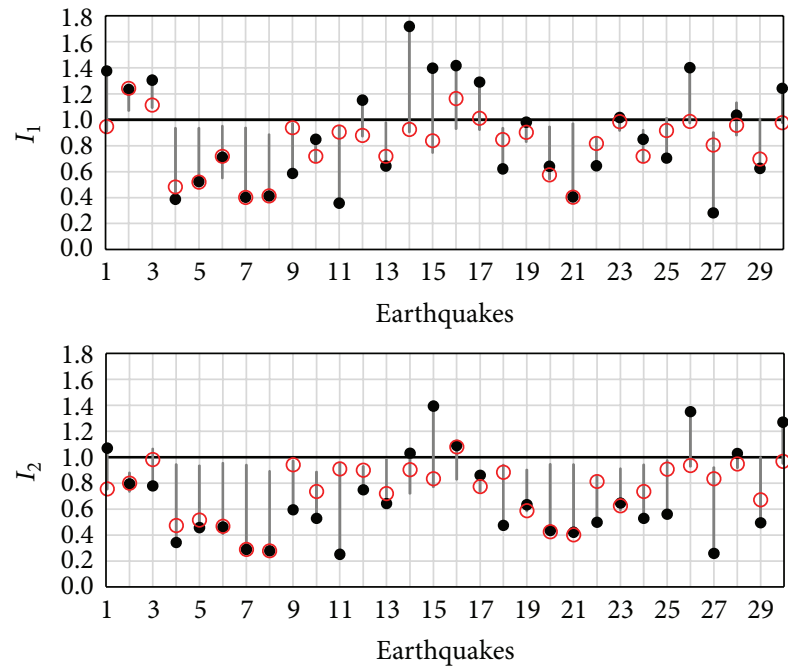

FIGURE 8: Italy: performance indices for the smart passive strategy (red circles) compared to the pure passive ones (black dots).

a performance index $I_{2}$ greater than 1 (i.e., to a midspan displacement greater than in the uncontrolled case).

Each of the above 961 possible calibrations of the control law has been evaluated according to the set of 6 criteria, finally allowing ranking of those alternatives by means of the TOPSIS method. The resulting optimal $(\alpha, \beta)$ combinations are

(i) $\alpha=0.56$ and $\beta=0.16$ for Italy (with $u_{c, \max }=4 \mathrm{~V}$ );

(ii) $\alpha=0.60$ and $\beta=0.14$ for California (with $u_{c, \max }=$ $10 \mathrm{~V})$.

The so-defined control algorithms for the Italian and Californian regions are expressed in (6) and (7) and graphically shown in Figure 7. The structural performances, in terms of $I_{1}$ and $I_{2}$, achieved by the smart passive strategies are shown in Figures 8 and 9, together with those corresponding to the passive cases, for comparison. Such comparison can also be made analytically by reading Table 4 , in which the evaluation of both passive and smart passive strategies according to the above six criteria is reported. 
TABLE 4: Evaluation of the smart passive strategy according to the six criteria (the values between brackets are the indices calculated for the pure passive control case).

\begin{tabular}{lcccccc}
\hline \multirow{2}{*}{ Region } & $C_{1}$ & $C_{2}$ & $C_{3}$ & $C_{4}$ & $C_{5}$ & $C_{6}$ \\
& $\mu\left(I_{1}\right)$ & $\mu\left(I_{2}\right)$ & $\sigma\left(I_{1}\right)$ & $\sigma\left(I_{2}\right)$ & $I_{1}>1$ & $I_{2}>1$ \\
\hline Italy & $0.82(0.87)$ & $0.74(0.67)$ & $0.22(0.40)$ & $0.22(0.33)$ & $4(12)$ & $1(7)$ \\
California & $0.81(0.79)$ & $0.74(0.58)$ & $0.17(0.29)$ & $0.21(0.28)$ & $2(8)$ & $0(3)$ \\
\hline
\end{tabular}
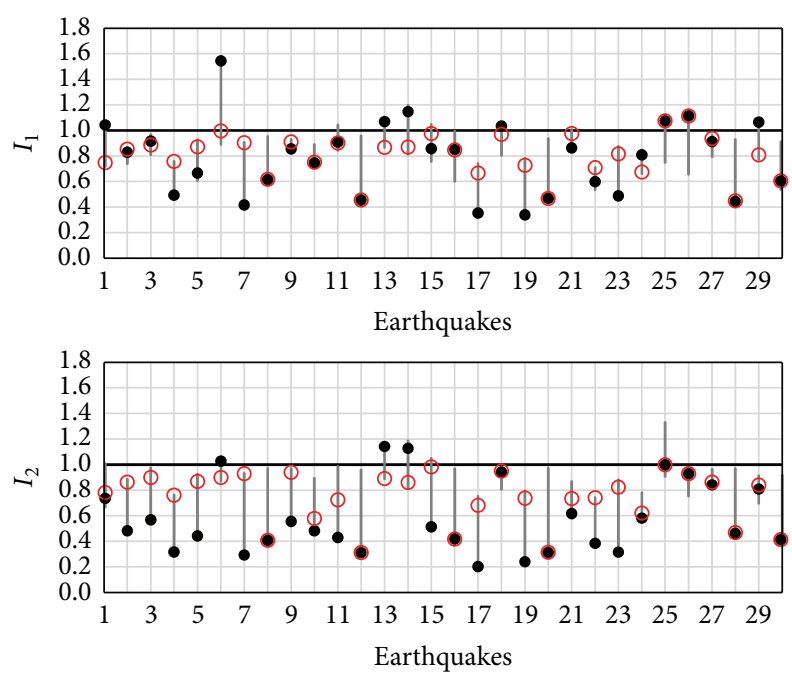

FIGURE 9: California: performance indices for the smart passive strategy (red circles) compared to the pure passive ones (black dots).

In Italy,

$$
\begin{aligned}
& u_{c}\left[S_{a}\left(T_{1}\right)\right] \\
& =2 \\
& \quad \cdot\left[1+\tanh \left(\frac{S_{a}\left(T_{1}\right)-0.56}{0.16}\right)\right] \text { with } S_{a}\left(T_{1}\right) \text { in } g .
\end{aligned}
$$

In California,

$$
\begin{gathered}
u_{c}\left[S_{a}\left(T_{1}\right)\right] \\
=5
\end{gathered}
$$

$$
\cdot\left[1+\tanh \left(\frac{S_{a}\left(T_{1}\right)-0.60}{0.14}\right)\right] \text { with } S_{a}\left(T_{1}\right) \text { in g. }
$$

The following comments can be made in reference to the data in Table 4:

(i) Criterion $C_{1}$ : both pure passive and smart passive control strategies lead to a significant reduction of the bending moment demand on the pier (approximately $20 \%$ on average).

(ii) Criterion $\mathrm{C}_{2}$ : the optimal passive strategy leads to an average reduction of $33 \%$ and $42 \%$ with respect to the uncontrolled case for Italy and California, respectively, while the smart passive strategy leads to a still significant reduction, even if it is lower
(26\% for both regions). This was expected because the optimal passive voltages $(3.75 \mathrm{~V}$ for Italy and $10.00 \mathrm{~V}$ for California) correspond to a high damping setting for the MR. Roughly speaking, considering that the magnetorheological effect due to voltage is strongly nonlinear with the voltage, the MR devices set at those levels of voltage behave as very "stiff" links between the deck and the abutments, leading to a displacement reduction that is hardly improvable.

(iii) Criteria $C_{3}, C_{4}$ : the smart passive strategy strongly reduces the variability of the response reduction with respect to the seismic input; actually, the standard deviations of both indices $I_{1}$ and $I_{2}$ evaluated for both sets of Italian and Californian earthquakes are significantly lower than those corresponding to the passive strategy;

(iv) Criteria $C_{5}, C_{6}$ : the smart passive strategy further strongly reduces the occurrence of cases for which the control technique worsens the structural performance in comparison to the uncontrolled system. This is in terms of both the bending moment on the piers and (even more so) the displacement demand.

These comments aim to conclude the adopted optimization procedure performed correctly, in the sense that it was able to lead to the definition of smart strategies having the main peculiar features of a semiactive control system: a strongly reduced variability of the response against different earthquakes and a drastic reduction of the incidence of undesired responses (i.e., controlled response higher than uncontrolled one), with average values of the performance indices not so far from those already achievable by a (simpler) pure passive control system.

From Figures 8 and 9, it is also worth noting how the performances of the smart control strategy (circles) are "positioned" for each earthquake of the 2 sets in comparison with those of the optimal passive strategy (dots) and, for completeness, also with those of all of the possible passive strategies (grey lines) based on the use of the devices in question. More in detail, it is interesting to observe how the "bandwidth" of the $I_{1}$ and $I_{2}$ values is significantly reduced for the smart passive strategy and how the trend is "pushing down" the values corresponding to the worst performances (i.e., indices greater than 1) of the optimal passive technique.

\section{Conclusions}

A smart passive control technique for the seismic protection of structures, based on the use of variable MR-fluid-based dampers and exploitation of a SEWS, has been proposed. 
The design procedure needed to implement such a system in a real case has been generated and also practically applied to two case studies.

The numerical results of the above application demonstrate the high effectiveness of the proposed procedure in reducing the structural demand due to strong earthquakes. Regional control algorithms played a central role in accomplishing that. Full achievement of all of the typical goals for a semiactive control strategy has been observed. With reference to the case study applications, it was demonstrated that the proposed control system allows for significant reductions of the average structural response (20-25\%) and, above all, that it is able to strongly reduce the variability of the response with the seismic input. Finally, in only a few cases (roughly one in ten) were the performances worse than those of the uncontrolled case. Even more importantly, in such critical cases, the proposed strategy led to performance index values that were only slightly greater than one, thus allowing for the conclusion that even when, in rare cases, the smart control is not beneficial, it is still definitely far from being detrimental to the structure, which cannot be said about pure passive systems.

Even if designed with reference to a given case study, the authors believe the regional control algorithms are potentially valid to drive variable dampers in effectively protecting any structure from earthquakes. Obviously, the number and strength capability of the MR devices obviously have to be defined according to the specific features of the case. A preliminary confirmation of such interpretation recently came from the satisfactory results achieved using the Italian regional controller applied to a real bridge located in southern Italy [62].

\section{Competing Interests}

The authors declare that they have no competing interests.

\section{Acknowledgments}

The work behind this paper has been financially supported by the consortium Reluis with a 2014-18 Grant by the Protezione Civile (Italian Emergency Agency) and by the University of Naples "Parthenope" with a grant within the call "Support for Individual Research for the 2015-17 Period" issued by Rectoral Decree no. 727/2015. The support of both is gratefully acknowledged.

\section{References}

[1] Earthquake Engineering Research Institute (EERI), Learning from Earthquakes Reconnaissance Archive, Earthquake Engineering Research Institute (EERI), Oakland, Calif, USA, 2015, https:// www.eeri.org/projects/learning-from-earthquakes-lfe/lfe-reconnaissance-archive/.

[2] A. Agrawal, P. Tan, S. Nagarajaiah, and J. Zhang, "Benchmark structural control problem for a seismically excited highway bridge-part I: phase I problem definition," Structural Control and Health Monitoring, vol. 16, no. 5, pp. 509-529, 2009.
[3] P. Tan and A. K. Agrawal, "Benchmark structural control problem for a seismically excited highway bridge-part II: phase I sample control designs," Structural Control and Health Monitoring, vol. 16, no. 5, pp. 530-548, 2009.

[4] S. Nagarajaiah, S. Narasimhan, A. Agrawal, and P. Tan, "Benchmark structural control problem for a seismically excited highway bridge-part III: phase II sample controller for the fully base-isolated case," Structural Control and Health Monitoring, vol. 16, no. 5, pp. 549-563, 2009.

[5] H.-J. Jung, D.-D. Jang, K.-M. Choi, and S.-W. Cho, "Vibration mitigation of highway isolated bridge using MR damper-based smart passive control system employing an electromagnetic induction part," Structural Control and Health Monitoring, vol. 16, no. 6, pp. 613-625, 2009.

[6] S.-W. Cho, H.-J. Jung, and I.-W. Lee, "Smart passive system based on magnetorheological damper," Smart Materials and Structures, vol. 14, no. 4, pp. 707-714, 2005.

[7] M. H. Pradono, H. Iemura, A. Igarashi, A. Toyooka, and A. Kalantari, "Passively controlled MR damper in the benchmark structural control problem for seismically excited highway bridge," Structural Control and Health Monitoring, vol. 16, no. 6, pp. 626-638, 2009.

[8] S. F. Ali and A. Ramaswamy, "Optimal dynamic inversion-based semi-active control of benchmark bridge using MR dampers," Structural Control and Health Monitoring, vol. 16, no. 5, pp. 564585, 2009.

[9] F. Casciati, L. Faravelli, and R. A. Saleh, "An SMA passive device proposed within the highway bridge benchmark," Structural Control and Health Monitoring, vol. 16, no. 6, pp. 657-667, 2009.

[10] Y. Zhang, X. Hu, and S. Zhu, "Seismic performance of benchmark base-isolated brdiges with superelastic $\mathrm{Cu}$-Al-Be restraining damping device," Structural Control and Health Monitoring, vol. 16, no. 6, pp. 668-685, 2009.

[11] G. Pujol, L. Acho, F. Pozo, and J. Rodellar, "A nonlinear damping control for the vibration mitigation of the benchamark highway bridge," Structural Control and Health Monitoring, vol. 16, pp. 586-598, 2009.

[12] X.-L. Ning, P. Tan, D.-Y. Huang, and F.-L. Zhou, "Application of adaptive fuzzy sliding mode control to a seismically excited highway bridge," Structural Control and Health Monitoring, vol. 16, no. 6, pp. 639-656, 2009.

[13] S. N. Madhekar and R. S. Jangid, "Variable dampers for earthquake protection of benchmark highway bridges," Smart Materials and Structures, vol. 18, no. 11, Article ID 115011, 2009.

[14] S. N. Madhekar and R. S. Jangid, "Use of pseudo-negative stiffness dampers for reducing the seismic response of bridges: a benchmark study," Bulletin of Earthquake Engineering, vol. 10, no. 5, pp. 1561-1583, 2012.

[15] S. N. Madhekar and R. S. Jangid, "Control of seismically excited benchmark highway bridge with variable frequency pendulum isolator," International Journal of Structural Engineering, vol. 3, no. 1-2, pp. 83-117, 2012.

[16] S. Narasimhan, "Robust direct adaptive controller for the nonlinear highway bridge benchmark," Structural Control and Health Monitoring, vol. 16, no. 6, pp. 599-612, 2009.

[17] Y.-J. Cha and A. K. Agrawal, "Velocity based semi-active turboLyapunov control algorithms for seismically excited nonlinear smart structures," Structural Control and Health Monitoring, vol. 20, no. 6, pp. 1043-1056, 2013.

[18] Q. Sun, L. Zang, J. Zhou, and Q. Shi, "Experimental study of the semi-active control of building structures using the shaking 
table," Earthquake Engineering and Structural Dynamics, vol. 32, no. 15, pp. 2353-2376, 2003.

[19] Z. Li and L. Xu, "Shaking-table test on semi-active control for seismic response of tall buildings using MRF-04K damper," in Proceedings of the 13th World Conference on Earthquake Engineering, Paper no. 3191, Vancouver, Canada, 2004.

[20] D. Zhao and H. Li, "Shaking table tests and analyses of semiactive fuzzy control for structural seismic reduction with a piezoelectric variable-friction damper," Smart Materials and Structures, vol. 19, no. 10, Article ID 105031, 2010.

[21] R. Franco-Anaya, A. J. Carr, and J. G. Chase, "Shaking table tests of a model structure with semi-active resettable devices," in Proceedings of the 10th U.S. National Conference on Earthquake Engineering Frontiers of Earthquake Engineering, Anchorage, Alaska, USA, 2014.

[22] N. Caterino, M. Spizzuoco, and A. Occhiuzzi, "Shaking table testing of a steel frame structure equipped with semi-active MR dampers: comparison of control algorithms," Smart Structures and Systems, vol. 15, no. 4, pp. 963-995, 2015.

[23] B. F. Spencer Jr. and S. Nagarajaiah, "State of the art of structural control," ASCE Journal of Structural Engineering, vol. 129, no. 7, pp. 845-856, 2003.

[24] N. Caterino, B. M. Azmoodeh, and A. Occhiuzzi, "Medium to long term behavior of MR dampers for structural control," Smart Materials and Structures, vol. 23, no. 11, Article ID 117005, 2014.

[25] A. Occhiuzzi, V. F. Grasso, and G. Manfredi, "Early warning systems from a structural control perspective," in Proceedings of the 3rd European Conference on Structural Control, Wien, Austria, July 2004.

[26] A. Occhiuzzi, I. Iervolino, and G. Manfredi, "Feedforward control algorithms for seismic early warning systems," in Proceedings of 4th World Conference on Structural Control and Monitoring, 4WCSCM-266, San Diego, Calif, USA, 2006.

[27] G. Maddaloni, N. Caterino, and A. Occhiuzzi, "Semi-active control of the benchmark highway bridge based on seismic early warning systems," Bulletin of Earthquake Engineering, vol. 9, no. 5, pp. 1703-1715, 2011.

[28] G. Maddaloni, N. Caterino, G. Nestovito, and A. Occhiuzzi, "Use of seismic early warning information to calibrate variable dampers for structural control of a highway bridge: evaluation of the system robustness," Bulletin of Earthquake Engineering, vol. 11, no. 6, pp. 2407-2428, 2013.

[29] M. D. Symans and M. C. Constantinou, "Semi-active control systems for seismic protection of structures: a state-of-the-art review," Engineering Structures, vol. 21, no. 6, pp. 469-487, 1999.

[30] N. Caterino, M. Spizzuoco, and A. Occhiuzzi, "Understanding and modelling the physical behaviour of magnetorheological dampers for seismic structural control," Smart Materials and Structures, vol. 20, no. 6, Article ID 065013, 2011.

[31] G. Iannaccone, A. Zollo, L. Elia et al., "A prototype system for earthquake early-warning and alert management in southern Italy," Bulletin of Earthquake Engineering, vol. 8, no. 5, pp. 11051129, 2010.

[32] Y. Nakamura, "Development of earthquake early-warning system for the Shinkansen, some recent earthquake engineering research and practical in Japan," in The Japanese National Committee of the International Association for Earthquake Engineering, pp. 224-238, 1984.

[33] Y. Nakamura, "On the urgent earthquake detection and alarm system (UrEDAS)," in Proceedings of the 9th World Conference
Earthquake Engineering, vol. 7, pp. 673-678, Tokyo, Japan, August 1988.

[34] T. Odaka, K. Ashiya, S. Tsukada, S. Sato, K. Ohtake, and D. nozaka, "A new method of quickly estimating epicentral distance and magnitude from a single seismic record," Bulletin of the Seismological Society of America, vol. 93, no. 1, pp. 526-532, 2003.

[35] S. Horiuchi, H. Negishi, K. Abe, A. Kamimura, and Y. Fujinawa, "An automatic processing system for broadcasting earthquake alarms," Bulletin of the Seismological Society of America, vol. 95, no. 2, pp. 708-718, 2005.

[36] Y.-M. Wu and T.-L. Teng, "A virtual subnetwork approach to earthquake early warning," Bulletin of the Seismological Society of America, vol. 92, no. 5, pp. 2008-2018, 2002.

[37] Y.-M. Wu and L. Zhao, "Magnitude estimation using the first three seconds P-wave amplitude in earthquake early warning," Geophysical Research Letters, vol. 33, no. 16, Article ID L16312, 2006.

[38] J. M. Espinosa-Aranda, A. Cuellar, A. Garcia et al., "Evolution of the mexican seismic alert system (SASMEX)," Seismological Research Letters, vol. 80, no. 5, pp. 694-706, 2009.

[39] R. M. Allen and H. Kanamori, "The potential for earthquake early warning in Southern California," Science, vol. 300, no. 5620, pp. 786-789, 2003.

[40] R. M. Allen, H. Brown, M. Hellweg, O. Khainovski, P. Lombard, and D. Neuhauser, "Real-time earthquake detection and hazard assessment by ElarmS across California," Geophysical Research Letters, vol. 36, no. 5, Article ID L00B08, 2009.

[41] R. M. Allen, P. Gasparini, O. Kamigaichi, and M. Böse, “The status of earthquake early warning around the World: an introductory overview," Seismological Research Letters, vol. 80, no. 5, pp. 682-693, 2009.

[42] M. Böse, E. Hauksson, K. Solanki, H. Kanamori, and T. H. Heaton, "Real-time testing of the on-site warning algorithm in southern California and its performance during the July 292008 Mw5.4 Chino Hills earthquake," Geophysical Research Letters, vol. 36, no. 5, Article ID L00B03, 2009.

[43] H. Alcik, O. Ozel, N. Apaydin, and M. Erdik, "A study on warning algorithms for Istanbul earthquake early warning system," Geophysical Research Letters, vol. 36, no. 5, Article ID L00B05, 2009.

[44] M. Böse, C. Ionescu, and F. Wenzel, "Earthquake early warning for Bucharest, Romania: novel and revised scaling relations," Geophysical Research Letters, vol. 34, no. 7, Article ID L07302, 2007.

[45] H. S. Peng, Z. L. Wu, Y.-M. Wu, S. M. Yu, D. N. Zhang, and W. Huang, "Developing a prototype earthquake early warning system in the Beijing capital region," Seismological Research Letters, vol. 82, no. 3, pp. 394-403, 2011.

[46] C. Satriano, L. Elia, C. Martino, M. Lancieri, A. Zollo, and G. Iannaccone, "PRESTo, the earthquake early warning system for Southern Italy: concepts, capabilities and future perspectives," Soil Dynamics and Earthquake Engineering, vol. 31, no. 2, pp. 137-153, 2011.

[47] I. Iervolino, M. Giorgio, C. Galasso, and G. Manfredi, "Uncertainty in early warning predictions of engineering ground motion parameters: what really matters?" Geophysical Research Letters, vol. 36, no. 5, Article ID L00B06, 2009.

[48] I. Iervolino, "Engineering earthquake early warning via regional networks," in Early Warning for Geological Disasters, Scientific Methods and Current Practice, F. Wenzel and J. Zschau, Eds., Springer, Berlin, Germany, 2014. 
[49] Q. Ma, X. Jin, and S. Li, "Ground shaking prediction for earthquake early warning," in Proceedings of the 15th World Conference of Earthquake Engineering (WCEE '12), Lisbon, Portugal, September 2012.

[50] R. M. Allen, "Rapid magnitude determination for earthquake early warning," in The Many Facets of Seismic Risk, G. Manfredi, M. R. Pecce, and A. Zollo, Eds., 2004.

[51] M. Hoshiba and S. Aoki, "Numerical shake prediction for earthquake early warning: data assimilation, real-time shake mapping, and simulation of wave propagation," Bulletin of the Seismological Society of America, vol. 105, no. 3, pp. 1324-1338, 2015.

[52] A. Zollo, S. Colombelli, L. Elia et al., "An integrated regional and on-site earthquake early warning system for southern italy: concepts, methodologies and performances," in Early Warning for Geological Disasters: Scientific Methods and Current Practice, F. Wenzel and J. Zschau, Eds., Advanced Technologies in Earth Sciences, pp. 117-137, Springer, Berlin, Germany, 2014.

[53] N. Caterino, M. Spizzuoco, and A. Occhiuzzi, "Promptness and dissipative capacity of MR dampers: experimental investigations," Structural Control and Health Monitoring, vol. 20, no. 12, pp. 1424-1440, 2013.

[54] ITACA, “Italian Acceleration Archive," http://itaca.mi.ingv.it.

[55] PEER, "Pacific Earthquake Engineering Research Center," http:// peer.berkeley.edu/smcat/.

[56] Eurocode 8, Design of Structures for Earthquake ResistancePart 1: General Rules, Seismic Actions and Rules for Buildings, Brussels, Belgium, 2003.

[57] C. L. Hwang and K. Yoon, Multiple Attribute Decision Making: Methods and Applications, Springer, New York, NY, USA, 1981.

[58] K. Yoon, "A reconciliation among discrete compromise situations," Journal of the Operational Research Society, vol. 38, no. 3, pp. 277-286, 1987.

[59] C.-L. Hwang, Y.-J. Lai, and T.-Y. Liu, "A new approach for multiple objective decision making," Computers and Operations Research, vol. 20, no. 8, pp. 889-899, 1993.

[60] N. Caterino, I. Iervolino, G. Manfredi, and E. Cosenza, "Comparative analysis of multi-criteria decision-making methods for seismic structural retrofitting," Computer-Aided Civil and Infrastructure Engineering, vol. 24, no. 6, pp. 432-445, 2009.

[61] N. Caterino, I. Iervolino, G. Manfredi, and E. Cosenza, "Multicriteria decision making for seismic retrofitting of RC structures," Journal of Earthquake Engineering, vol. 12, no. 4, pp. 555583, 2008.

[62] I. Nuzzo, N. Caterino, G. Maddaloni, and A. Occhiuzzi, "Hybrid isolation of highway bridge via FPS and MR dampers exploiting seismic early warning information," in Proceedings of the XVI ANIDIS Conference, L'Aquila, Italy, 2015. 


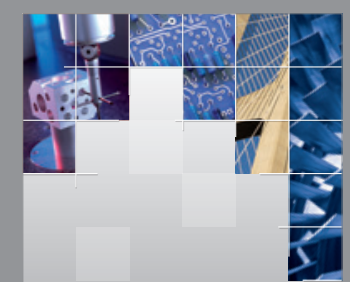

\section{Enfincering}
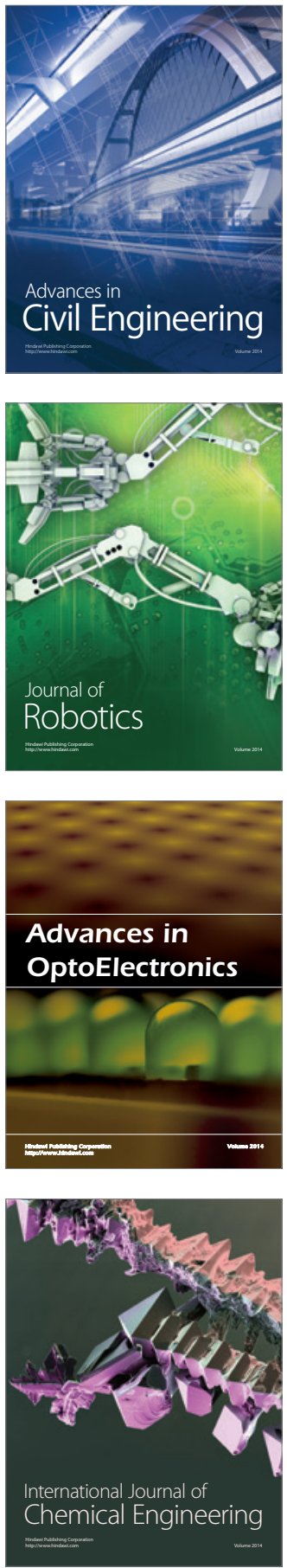

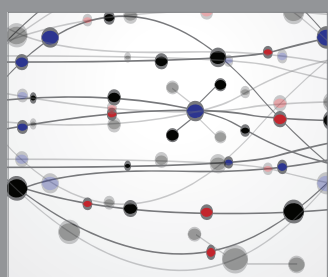

The Scientific World Journal

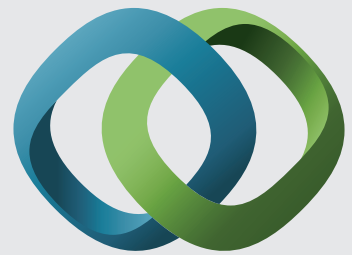

\section{Hindawi}

Submit your manuscripts at

http://www.hindawi.com
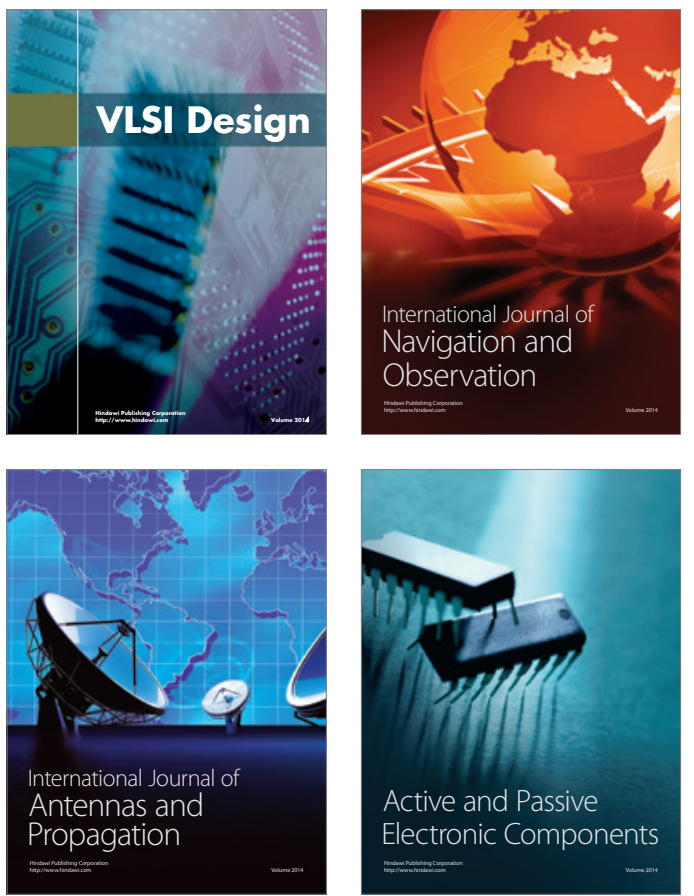
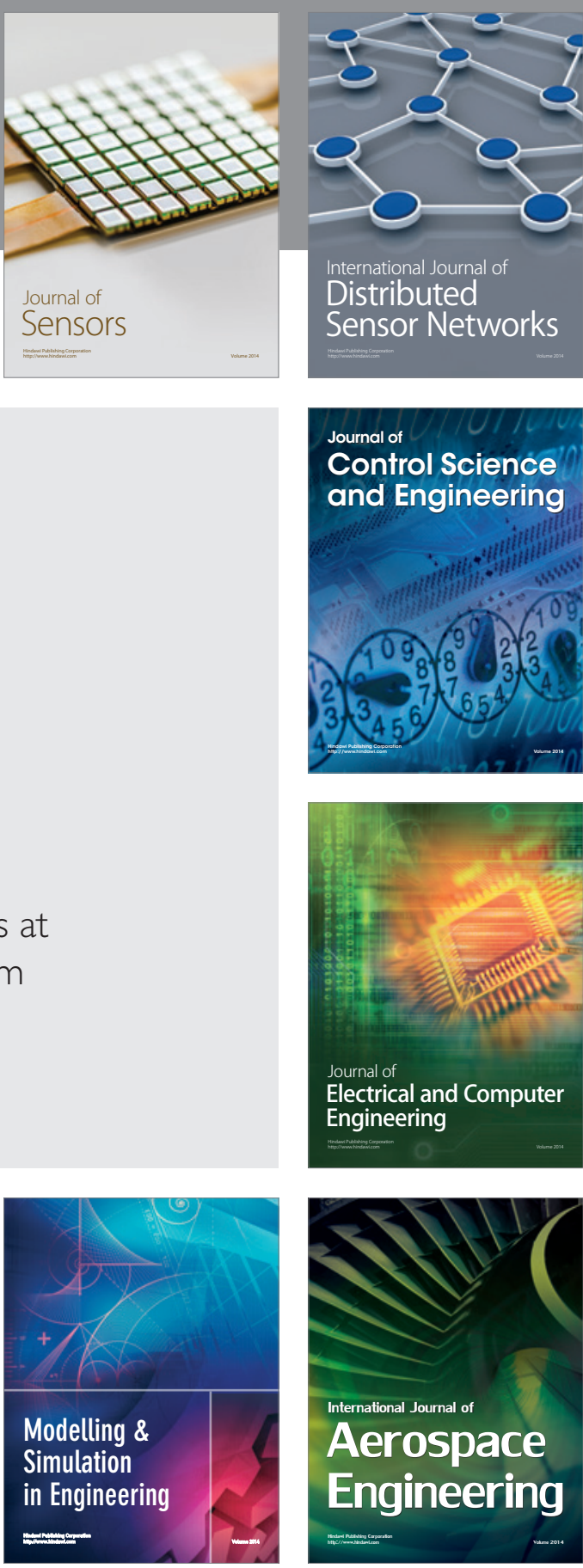

International Journal of

Distributed

Sensor Networks

Journal of

Control Science

and Engineering
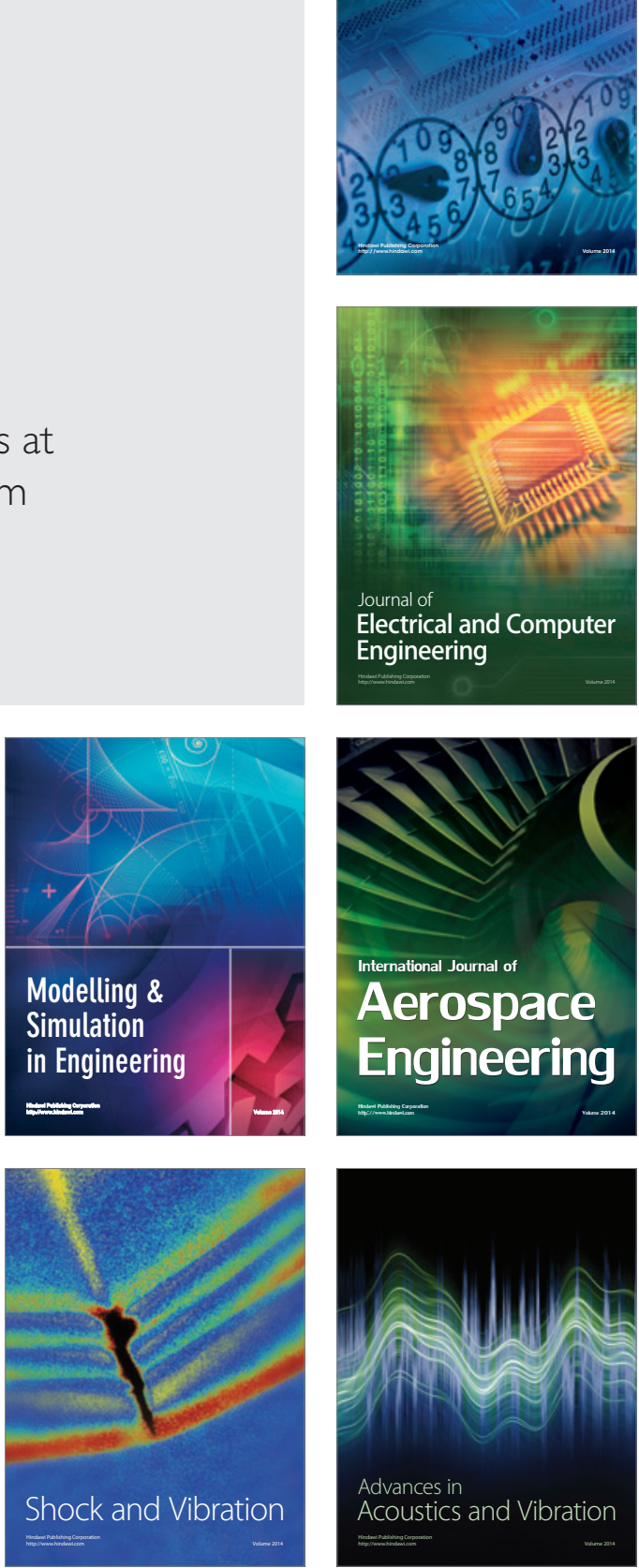